\title{
"Oral Hygiene Practice and Health Status among Adolescent Girls - A Rural School Based Study"
}

\author{
Dr Nirmalya Manna ${ }^{1}$, Dr Soumi Biswas ${ }^{2}$,Dr Dipanwita Pandit ${ }^{2,}$ Dr Kakali \\ Mondal $^{2,}$ Dr Baijayanti Baur ${ }^{3,}$ Dr Malay Mundle ${ }^{4}$ \\ ${ }^{1}$ Assistant Professor, ${ }^{2}$ Post Graduate trainee,${ }^{3}$ Professor, ${ }^{4}$ Professor and Head \\ ${ }^{I}$ Department of Community Medicine, Medical College, Kolkata, India \\ ${ }^{3}$ Department of Community medicine, Medinipur Medical College
}

\begin{abstract}
India has a high prevalence of dental caries ranging from 60 to $75 \%$. The World Health Organization goal for "Health for All" was to lower the DMFT (Decay Missed Filling Teeth) score to less than 3. The objectives of the present study were to observe oral health status, hygiene practice and their relationship among adolescent girls in Tarakeswar block. This cross sectional study was done on 132 rural girls selected by systematic sampling and assessed by DMFT score and SiC index (Significant Caries index). Dental caries index was 37.1\%, mean DMFT score was 0.78 and Sic index was 2.02 among the study population. Gum problems were significantly associated with difficulty in biting and chewing food, malalignment and knowledge of tooth decay cause. DMFT status was significantly associated with frequency of brushing and methods of tooth cleaning. Promotion of school dental health programmes by teachers would go a long way in achieving good oral health status.
\end{abstract}

Key Words: Oral health, DMFT, SiC index, adolescent girls

\section{Introduction}

School children of today are the adults of tomorrow. So they require special care. Oral health problems such as dental and gum disease, affect the ability to eat, communicate and perform other daily activities. In 2007 the WHO reported that $60-90 \%$ of school children worldwide have dental caries [D. Marcia et al.(2011)]. The prevalence of dental caries is approximately $60 \%-65 \%$ in India [K Abdul et al. (2008)]. The impact of poor oral hygiene is observed at school and the workplace, with the loss of millions of work hours worldwide. Dental caries and periodontal diseases are the most common oral diseases showing striking geographic variations, socio-economic patterns and severity of distribution all over the world [R Balwant et al.(2007)]. Dental hygiene is poor in India with improper brushing of teeth, no washing of mouth after intake of sweets, wide-spread addiction, hyperacidity, increased consumption of refined sugar and sweetened foods [Soren AB et al. (2011)]. Improving oral health in especially rural children is still a dream come true in a developing country like India. Deprived communities that suffer the most and so have the most need, receive the fewest resources [VC Punitha, P Sivaprakasam (2011)]. About 72\% of the Indian population living in rural areas with no access to the private dental health sector [AH Fatima, C Ravikumar (2009)]. According to the Centers for Disease Control and Prevention (CDC), more than 19 percent of children have untreated cavities and approximately 41 percent of children have decay in their "baby teeth" [S B David (2012)]. There is increasing evidence linking impaired oral hygiene to various health conditions such as pancreatic cancer in men, stroke/transient ischemic attacks, type I and II diabetes, low birth weight and pre-term deliveries [AH Fatima, C Ravikumar (2009)]. Indian medicine (Ayurveda) has used the neem tree, or daatun and its products to create teeth cleaning twigs. In the Muslim world, the miswak, or siwak, made from a twig or root, has been widely used since the Islamic Golden Age [S Abhinav, P Bharati (2011)]. There is paucity of information regarding the frequency and prevalence of dental caries and oral hygiene status among school children in many parts of India. Keeping this background in mind the present study was undertaken with the following objectives:

1. To observe oral health status among adolescent girls

2. To study oral hygiene practice among the study population.

3. To find out relation between oral hygiene practice and health status.

\section{Methodology}

It was an observational, cross-sectional study conducted among school girls in Tarakeswar block, located in one of the peripheral districts of West Bengal. The duration of the study was 3 months (Dec 2012-Feb 2013). The school children were selected as the study group because of easy accessibility and availability. Out of 4 girls' school in Tarakeswar block, Ramnagar Vidyasagar balika Vidyalaya was randomly selected. Students of Class 8 to 12 of that particular school were included in the study. School authority was informed 
about the purpose of the study and permission was taken. Informed verbal consent was taken from the students and from the teachers (for students below 18 years age) before interview. Anonymity and confidentiality of the students were ensured. Those students who were unwilling to participate or absent on examination day were excluded from this study. They were interviewed using pre-designed and pre-tested semi-structured questionnaire in vernacular before dental examination. Researchers were oriented and trained for 7 days in R. Ahmed Dental College regarding Oro-dental examination. The students were examined in the classroom with sufficient natural daylight. Decay Missed Filling Teeth (DMFT) and Significant Caries Index (Sic index) were used for assessment of oral health status [www.mah.ac]. DMFT is calculated by adding the number of decayed (D), missing (M), and Filled (F) teeth and expresses the individual's dental caries experience until the day of examination. Because $3^{\text {rd }}$ molars erupt at approximately age 17 years (average between ages 15-25), these teeth were excluded from the DMFT calculation in this population. The sum of all the DMFT values divided by the total number of individuals in the sample provides the mean DMFT for the population. Sic index was calculated by taking mean of $1 / 3$ population having highest DMFT. The SiC Index is an indicator that reflects the situation among the most caries-exposed individuals. Taking the prevalence of dental caries to be $60 \%$ with $15 \%$ allowable error and 10\% non-response, the sample size came to be 132 [K Abdul et. al (2008)]. Total 416 students were present according to enrollment. Among these every third student was interviewed by systematic sampling. Therefore total 138 students were interviewed. Due to incompleteness of response by 6 patients, finally 132 schedules were used for analysis. Data was tabulated in Microsoft Excel 2010 spread sheet \& analyzed by appropriate statistical methods in SPSS 19 software.

\section{Results}

Majority of the study population were in 14 to 15 years age group. Only $20.5 \%$ of fathers and $10.6 \%$ of mothers had higher education. About $5.3 \%$ of the study population said they had poor health of their teeth. However $47.7 \%$ were not satisfied with their teeth (mostly due to malalignment) and $35.6 \%$ avoid smiling due to this. $3.8 \%$ of the study population was addicted to betel quid. Majority $(73 \%)$ of the study population said they had good health of their gums. About $58 \%$ of the study population complained of having toothache in the past one year. About $23.5 \%$ of the study population at least missed a class due to toothache. Statistically significant association was observed between frequency of toothache and malalignment $(\mathrm{p}<0.05)$. About $67.4 \%$ study population (89) used toothbrush and toothpaste regularly for tooth cleaning. Other materials were floss $(2.3 \%)$, Plastic toothpick (2.3\%), Charcoal $(0.8 \%)$, Chew stick $(0.8 \%)$, Guraku $(2.3 \%)$ and a combination of these. $14.4 \%$ of the study population had difficulty in biting food and $18.2 \%$ had difficulty in chewing food. Gum problems were also significantly associated with difficulty in chewing food, malalignment and knowledge of tooth decay cause. $19 \%$ of the study population had complained of having cavities. $34.8 \%$ of the study population didn't know if they had cavities. Majority of the study population $(79.6 \%)$ had no idea what causes tooth decay. About $18.2 \%$ of the study population opined that tooth decay was caused by not brushing and $7.6 \%$ had an idea that cavity was the cause of tooth decay. Tongue cleaning was significantly associated with teeth stain $(\mathrm{p}<0.01)$ and method of teeth cleaning $(<0.01)$. Only $6.1 \%$ of the study population had knowledge about when to visit the dentist and $66.6 \%$ did not give any response. $46 \%$ of the study population knew that oral health was linked with other serious diseases. $3 \%$ of the study population had family history of oral cancer. $72.7 \%$ of the study population said that toothbrushes should be replaced every 2 to 3 months. Only $36.4 \%$ of the study population did brushing at night also. Among them $91.7 \%$ didn't eat/drink anything after night time brushing. Only $43 \%$ of the study population brushed their teeth for more than 2 minutes. $68.2 \%$ said that they had not been taught the importance of brushing regularly. $81.1 \%$ of the study population cleaned their tongue regularly. $30.3 \%$ of the study population suffered from 1 to 3 episodes of sore throat in the last six months. $50.8 \%$ of the study population never visited a dentist. Only $15.9 \%$ of the study population visited a dentist within a year. Among the study population who visited a dentist within 2 years, majority (71.4\%) visited due to extraction or filling. About $25 \%$ of the study population didn't know the reason for visiting a dentist as they were taken by their parents. $28.8 \%$ of the study population was having DMFT status 1 to 2 . Mean DMFT score was 0.78 . Dental caries index was $37.1 \%$ and Sic index was 2.02 .

\section{Discussion}

The present study highlighted the oral health status, hygiene practice, their relationship, the caries prevalence and severity trends among adolescents in Tarakeswar block using both the mean DMFT index and the SiC Index. The use of DMFT had been an accepted practice for assessing the prevalence and severity of caries in a population. Mean DMFT values were an average of all members of the population, irrespective of the distribution of the severity of the disease within the population [D. Marcia et al. (2011)]. Majority of the study population were in 14 to 15 years age group (mean $=14.23, \mathrm{SD}=1.21$ ) like the study done in Kerala among adolescents with a mean age of 14.05 and standard deviation of 1.92 years [Jayakumary M et al. (2009)]. About $3.8 \%$ of the study population was addicted to betel quid. In a study done at Bankura, dental hygiene was found 
to be poorest among persons addicted to Gurakhu, Gutkha and Pan Parag [Soren AB et al. (2011)]. About 58\% of the study population had complained of having toothache in the past one year and $23.5 \%$ of the study population missed a class due to toothache which was similar to the study done in Kanchipuram district where 59\% rural children consulted the dentist only due to pain [VC Punitha, P Sivaprakasam (2011)]. 67.4\% study population used toothbrush and toothpaste regularly compared to $76.4 \%$ in Bankura study [Soren AB et al. (2011)]. Gum problems were significantly associated with difficulty in biting and chewing food, malalignment and knowledge of tooth decay cause. Majority of the study population (79.6\%) had no idea what caused tooth decay. About $7.6 \%$ opined that cavity was the cause of tooth decay. None of the students mentioned sweets and chocolates to be the cause of tooth decay however more than half of the students in Kanchipuram were aware that eating sweets and chocolates could cause dental problems.16.04\% told that not brushing regularly could be one factor which was similar to our study. Only $4.8 \%$ children were aware that by regular brushing of teeth, dental problems could be prevented while in the present study the response was 18.2\% [VC Punitha, P Sivaprakasam (2011)]. 21.56\% children were not aware of how often to change their tooth brush though in our study majority (72.7\%) of the study population said that toothbrushes should be replaced every 2 to 3 months [VC Punitha, P Sivaprakasam (2011)]. Different studies in China observed that 2 times brushing was done by only 40 to $50 \%$ of teenagers while in our study only $36.4 \%$ did it for two times or more [ Jayakumary M et al. (2009)]. Another study in Pokhara had shown that only $1 \%$ brushed twice daily, $29 \%$ occasionally and $10 \%$ not brushing at all [ Baral P et al. (2009)]. Our study population used floss (2.3\%), Plastic toothpick (2.3\%), Charcoal $(0.8 \%)$, Chew stick $(0.8 \%)$ and Guraku $(2.3 \%)$ for tooth cleaning. Similarly in other studies burnt husk of paddy (7.4\%), neem twig (9.8\%), gurakhu (7.8\%), charcoal or mustard oil $(5.9 \%)$ were used for tooth cleaning [Soren AB et al. (2011), Jayakumary M et al. (2009)]. The study population in Kanchipuram (48.14\%) had suffered from some form of dental problem in the last one year. Among them 58.97\% consulted the dentist and pain was the main factor for consultation [VC Punitha, P Sivaprakasam (2011)]. However the present study reported that only $15.9 \%$ of the study population visited a dentist within a year. The World Health Organization (WHO) global goal for year 2000 for dental caries was of no more than an average of 3 DMFT [Sogi GM, Bhaskar DJ (2002)]. In this study 28.8\% of the study population was having DMFT status 1 to 2 and mean DMFT was 0.78. The mean DMFT for females was $3.27 \pm 2.65$ in Rohtak which reflected higher DMFT than our study [R Balwant et al. (2007)]. Mean DMFT by NHANES 1999-2004 in Nevada was 1.78 in 13 to 15 years age group and 3.31 in 16 to 19 years old [D Marcia et al. (2011)]. Dental caries index was $37.1 \%$ which was less than the total prevalence of India (60 to 65\%) and the study done in Nevada where $64.7 \%$ and $77.1 \%$ were suffering from dental caries in 1-15 years and 16-19 years respectively [D Marcia et al. (2011)]. Sic index was 2.02. The $\mathrm{SiC}$ Index was an indicator that reflected the situation among the most caries-exposed individuals. Majority of the study population (37.1\%) were having dental caries followed by $(25 \%)$ malalignment of teeth or jaws and $23.5 \%$ had brownish stain in tooth. $21.2 \%$ complained of bleeding gums. Frequency of toothache was significantly associated with malalignment. DMFT status was significantly associated with frequency of brushing and regular use of tooth paste ( $\mathrm{p}<0.01)$. A whopping $89 \%$ respondents in Delhi, $65 \%$ in Bengaluru, $25 \%$ in Kolkata and 19\% in Mumbai felt that India as a nation smiled less than other countries. $76 \%$ of dentists agree with the statement that patients with poor oral hygiene tend to smile less [www.pg.com]. In our study $35.6 \%$ study population avoid smiling due to malalignment.

\section{Conclusion}

Results of this study highlighted that oral hygiene habits, oral health awareness and knowledge level among rural schoolchildren was poor and needs to be improved. Using brush and dentifrices had led to better DMFT status than other traditional methods. Parents and teachers need to be informed, motivated about dental care so that their attitudes change. Exploring the links between oral health condition and their personal and social outcomes not only promotes a better appreciation of oral health, it also provides the opportunity to identify interventions to minimize the consequences of oral diseases by school dental health programmes. Detailed collaborative study is required to infer actual role of these associated factor in dental caries etiology. The data can be helpful for designing the preventive measures against dental caries on the basis of factors associated with it.

\section{Tables and Charts}

Table 1: Relationship between gum problems and difficulty in biting food $(n=132)$

\begin{tabular}{|c|c|c|c|c|c|c|}
\hline \multirow{2}{*}{$\begin{array}{c}\text { Difficulty in } \\
\text { biting food }\end{array}$} & \multicolumn{5}{|c|}{ Gum Problems } & \multirow{2}{*}{ Total Significance } \\
\cline { 2 - 6 } & None & Black & Bleeding & Swollen & 19 \\
\hline Yes & 17 & 0 & 2 & 0 & 113 \\
\hline No & 109 & 1 & 0 & 3 & 132 & $\mathrm{P}<0.01$ \\
\hline Total & 126 & 1 & 2 & 3 & 13 \\
\hline
\end{tabular}


"Oral Hygiene Practice and Health Status among Adolescent Girls - A Rural School Based Study"

Table 2: Distribution of study population according to DMFT status $(\mathrm{n}=132)$

\begin{tabular}{|c|c|c|}
\hline DMFT Status & Frequency & Percentage \\
\hline 0 & 83 & 14.4 \\
\hline 1 & 19 & 14.4 \\
\hline 2 & 19 & 2.3 \\
\hline 3 & 3 & 6.1 \\
\hline
\end{tabular}

Table 3: Distribution of study population according to oral health status $(n=132)^{*}$

\begin{tabular}{|l|c|c|}
\hline Oral health Status & Frequency & Percentage \\
\hline Caries & 49 & 47.1 \\
\hline Swollen gums & 21 & 15.9 \\
\hline Brown Stain & 31 & 23.5 \\
\hline Plaque & 20 & 15.2 \\
\hline Malalignment & 33 & 25.0 \\
\hline Tonsillitis & 18 & 13.6 \\
\hline
\end{tabular}

*Multiple Responses

Table 4: Association of DMFT score with frequency of brushing, regular use of tooth brush and knowledge about replacement of toothbrushes $(\mathrm{n}=132)$

\begin{tabular}{|c|c|c|c|c|c|}
\hline \multirow[b]{2}{*}{ Variables } & \multicolumn{4}{|c|}{ DMFT Score } & \multirow{2}{*}{$\begin{array}{c}\text { Significance } \\
\text { P Value }\end{array}$} \\
\hline & None & $\begin{array}{l}\text { Low } \\
(1-2)\end{array}$ & Moderate (3-4) & $\begin{array}{l}\text { High } \\
(\geq 5)\end{array}$ & \\
\hline $\begin{array}{l}\text { Frequency of brushing } \\
\geq 2 \text { times } \\
<2 \text { times }\end{array}$ & $\begin{array}{l}39 \\
44\end{array}$ & $\begin{array}{c}5 \\
33\end{array}$ & $\begin{array}{l}3 \\
5\end{array}$ & $\begin{array}{l}1 \\
2\end{array}$ & $<0.01$ \\
\hline $\begin{array}{l}\text { Regular use of tooth brush \& paste } \\
\text { Yes } \\
\text { No }\end{array}$ & $\begin{array}{l}73 \\
10\end{array}$ & $\begin{array}{c}9 \\
29\end{array}$ & $\begin{array}{l}5 \\
3\end{array}$ & $\begin{array}{l}2 \\
1\end{array}$ & $<0.01$ \\
\hline $\begin{array}{l}\text { Replacement of tooth brusheses } \\
2-3 \text { months } \\
>3 \text { months }\end{array}$ & $\begin{array}{l}60 \\
23\end{array}$ & $\begin{array}{l}28 \\
10\end{array}$ & $\begin{array}{l}6 \\
2\end{array}$ & $\begin{array}{l}2 \\
1\end{array}$ & 0.99 \\
\hline
\end{tabular}

Fig 1: Bar diagram showing distribution of study population according to perception of the status of teeth.

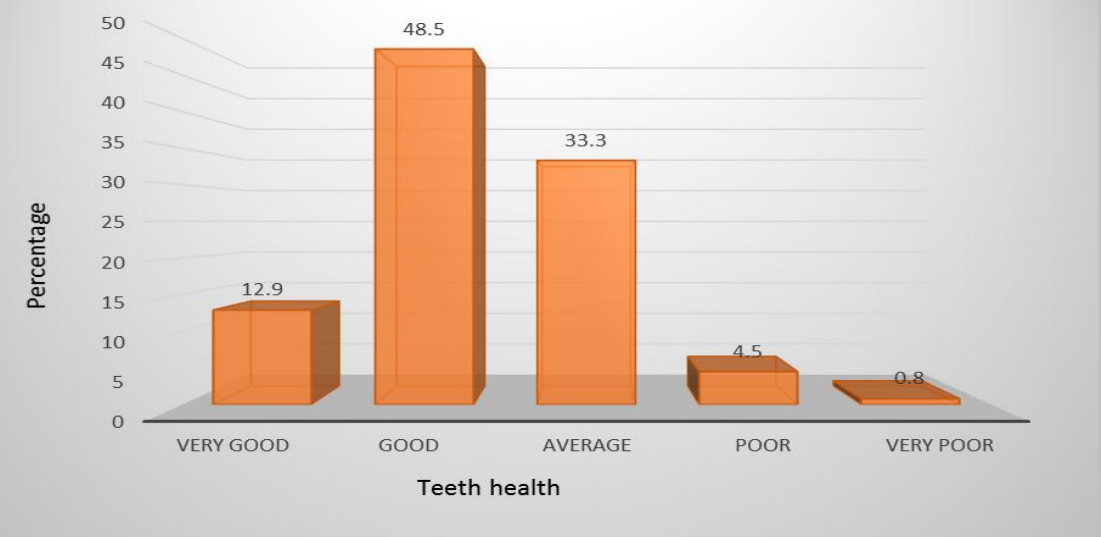

\section{References}

[1] AH Fatima, C Ravikumar (2009). Prevalence study of oral hygiene and dental health. IKP Centre for technologies in public health. Global internship program.1-2 (http://www.ictph.org.in/gip-2009/paper-4-introduction.html).

[2] Baral P et al. (2009). A Study on oral hygiene practice among school children of Pokhara municipality. Journal of GMC-Nepal. 2(2): $37-38$

[3] D Marcia et al. (2011). Inequalities of caries experience in Nevada youth expressed by DMFT index vs. Significant Caries Index ( $\mathrm{SiC})$ over time. BMC Oral Health. 11(12):1-10

[4] http://www.mah.se/CAPP/Methods-and Indices/for-Caries-prevalence/Significant Caries-Index/Online-Calculation-of DMFTdmftand-SIC-Index.

[5] http://www.pg.com/en_IN/downloads/news_media/The_Oral_B_Smile_Survey_by_AC_Nielsen.pdf AC Nielson. Is India smiling less due to Poor Oral Hygiene?

[6] Jayakumary M et al. (2009). Oral health behaviour among adolescents in Kerala, India. Italian Journal of Public Health.6 (3): 218224

[7] K Abdul et al. (2008). Prevalence of Dental Caries among the Population of Gwalior (India) in Relation of Different Associated Factors. Eur J Dent. 2:81-83. 
[8] R. Balwant et al. (2007). Dental caries and oral hygiene status of 8 to 12 year school children of Rohtak: A brief report. The Internet Journal of Dental Sciences. 5(1).

[9] S Abhinav and P Bharathi (2011).Tooth brushing, oil pulling and tissue regeneration: A review of holistic approaches to oral health. Journal of Ayurveda and integrative medicine. 2(2):64-68

[10] S B.David (2012). Dental hygiene important for whole body, not just your smile FoxNews.com. March 28.http://www.foxnews.com/health/2012/03/28/dental-hygiene-important-for-whole-body-not-just-your-smile

[11] Sogi GM, Bhaskar DJ (2002). Dental caries and Oral Hygiene Status of school children in Davangere related to their Socio Economic levels: An Epidemiological study. J Indian Soc Pedo Prev Dent December.20 (4): 152-157

[12] Soren AB et al. (2011). A study of dental hygiene and decayed, missed, and filled status among patients attending dental OPD of Bankura Sammilani Medical College, India. The Health. 2(4): 128-130

[13] VC Punitha, P Sivaprakasam (2011). Oral hygiene status, knowledge, attitude and practices of oral health among rural school children of kanchipuram district. Indian Journal of Multidisciplinary Dentistry. 1(2): 115-118 